\title{
Fluid-Structure Coupling Model and Experimental Validation of Interaction Between Pneumatic Soft Actuator and Lower Limb
}

\author{
Dong Guan, ${ }^{1,2}$ Rong Liu, ${ }^{1}$ Chengwei Fei, ${ }^{1,3}$ Shumi Zhao, and Lingxiao Jing ${ }^{1}$
}

\begin{abstract}
Pneumatic soft actuators (PSAs) are components that produce predesigned motion or force in different end-use devices. PSAs are lightweight, flexible, and compatible in human-machine interaction. The use of PSAs in compression therapy has proven promising in proactive pressure delivery with a wide range of dosages for treatment of chronic venous insufficiency and lymphedema. However, effective design and control of PSAs for dynamic pressure delivery have not been fully elaborated. The purpose of this study is to explore interactive working mechanisms between a PSA and lower limbs through establishing fluid-structure coupling models, an intermittent pneumatic compression (IPC) testing system, and conducting experimental validation. The developed IPC testing system consisted of a PSA unit (multichambered bladders laminated with an external textile shell), a pneumatic controller, and various real-time pressure monitoring sensors and accessory elements. The established coupling model characterized the dynamic response process with varying design parameters of the PSA unit, and demonstrated that the design of initial thickness, stiffness, and air mass flow of the PSA, as well as stiffness of limb tissues of the users, influenced PSA-lower limb interactions and resultant pressure dosages. The simulated results presented a favorable agreement with the experimental data collected by the IPC testing system. This study enhanced understanding of PSA-lower limb interactive working mechanisms and provided an evidence-based technical guidance for functional design of PSA. These results contribute to improving the efficacy of dynamic compression therapy for promotion of venous hemodynamics and user compliance in practice.
\end{abstract}

Keywords: pneumatic soft actuator, compression therapy, fluid-structure coupling model, experimental validation, lower limb

\section{Introduction}

Q OfT ACTUATORS ARE an integral component of soft robotic systems. This includes diverse pneumatic soft actuators (PSAs) fabricated from linear or nonlinear soft materials to generate numerous predesigned motions or forces.

PSAs have been widely investigated in terms of bionic design (artificial muscles, ${ }^{1-4}$ wearable exoskeleton, ${ }^{5}$ robotic fish, ${ }^{6}$ and climbing robot $^{7}$ ), material fabrication (textiles, ${ }^{8}$ soft composite material, ${ }^{9,10}$ silicone elastomers, ${ }^{11}$ soft gel, ${ }^{9}$ hybrid soft-rigid material, ${ }^{12}$ and dielectric elastomers ${ }^{13}$ ), prototype development (gripper, ${ }^{2,8,14-16}$ orthodontic application, ${ }^{17}$ minimally invasive surgery, ${ }^{12,18}$ variable stiffness endoskeleton, ${ }^{11}$ and robotic fish $^{2,6,13}$ ), product modeling, ${ }^{2,19-22}$ movement control, $2,5,23,24$ and biomedical applications (artificial muscles, ${ }^{16,25}$ sur- gery, ${ }^{12,26,27}$ and rehabilitation ${ }^{17,26,28-30}$ ). The powered PSAs by pneumatic pressure present advantages of lightweight, easy to fabricate, and inherent environment compliance.

A number of studies have attempted to apply PSAs in human limb and joint treatment. For example, Belforte et al. ${ }^{28}$ designed textile-based pneumatic artificial muscles for upper/ lower limb recovery. Park et al. ${ }^{5}$ designed a PSA-powered controllable and wearable robotic device for ankle-foot rehabilitation. Li et al. ${ }^{29,31-33}$ investigated effects of polyvinyl chloride gel soft actuator-based wearable assistive garments on hip joint support in walking. Singh and Xiao ${ }^{34-37}$ designed a soft pneumatic interface between a crutch and user's forearm using a fiber-reinforced elastomeric enclosure to decrease wrist and palmer loads. However, these studies mainly focused on fabrication and experimental testing without theoretical

\footnotetext{
${ }^{1}$ Institute of Textiles and Clothing, The Hong Kong Polytechnic University, Kowloon, Hong Kong.

${ }^{2}$ College of Mechanical Engineering, Yangzhou University, Yangzhou, China.

${ }^{3}$ Department of Aeronautics and Astronautics, Fudan University, Shanghai, China.
} 
models to demonstrate mechanical contacts between active garments and biological bodies.

Ghate et $a l .{ }^{38}$ designed and developed a bendable PSA prototype for surgical application and devised a mathematical model to characterize its mechanical behavior. However, this model is a fourth-degree polynomial approximation equation that does not incorporate specific physical connotations. Low et al..$^{39}$ developed a soft pneumatic sock as an alternative mechanical prophylaxis to assist a robot's ankle joint motion. However, this model cannot real-time detect effects of a pneumatic control (e.g., air mass flow) on joint mechanical function. Young and Ferris ${ }^{40}$ critically reviewed the existing lower limb robotic exoskeletons, and indicated that rigorous quantitative evaluations on exoskeleton performance were rarely reported, which limited understanding on disadvantages and drawbacks of the tested devices.

In recent studies, researchers have further integrated numerical simulation and experimental tests to validate PSA prototype design in locomotion and grippers, ${ }^{16}$ robot-assisted ankle exercise, ${ }^{35}$ and linear motion and bending. ${ }^{41}$ However, the aforementioned studies are irrelevant to the pneumatic compression therapy of lower extremities.

With the increase in the aging population and incidences of venous disorders, compression therapy has been widely applied for prophylaxis and treatment of vascular disorders (e.g., varicose veins, deep vein thrombosis, and lymphatic edema), wound management, and pain relief. ${ }^{42}$ The global compression therapy market size was valued at USD 2.9 billion in 2016 and is expected to witness a lucrative compound annual growth rate of 5.2\% between 2018 and $2025 .{ }^{43}$ Dynamic compression therapy using PSAs powered by an intermitted electronic pump to control pressure dosage delivery to lower limbs has been demonstrated to reduce venous stasis, ${ }^{44,45}$ promote blood flow, ${ }^{46,47}$ stimulate fibrinolytic activity, ${ }^{48,49}$ and cure venous ulceration. ${ }^{50,51}$

In recent years, pneumatic compression therapy has been recommended as an alternative to treat patients who could not use conservative measures (e.g., compression stockings or bandages) that offer sustained static pressures. The modalities of PSAs can be boots, sleeves, and other garment types, which mimic muscular contraction that occurs naturally when walking for hemodynamic promotion.

The girth and curvature of limb surface as well as stiffness of limb tissue influence pressure dosage delivery. In pneumatic compression therapy, rhythmic pressure is applied uniformly to the calf by either an inflated single-chambered (single-bladder) or multichambered PSA (multibladder) device for venous emptying. ${ }^{52}$ The PSA unit also can be constructed as either circumferential or noncircumferential ("asymmetric") ${ }^{53}$ around lower limb. The circumferential bladders encompass limb tissue, which commonly requires larger and powerful pneumatic air pumps or slower inflation rates. Whereas the asymmetric bladders compress along part of the circumference of the limb (e.g., posterior aspect) requiring a lower pneumatic air input (Fig. 1). The PSA shape must be
FIG. 1. Schematic presentation of PSA-lower limb system. (a) PSA unit with circumferentially set multibladders to lower limb. (b) Biomechanical pressure by PSA delivered to lower limb tissue system for hemodynamic promotion. (c) Asymmetric PSA unit with single pneumatic bladder set at posterior limb. (d) Circumferential PSA unit with sequential gradient pneumatic bladders set around limb. PSA, pneumatic soft actuator. Color images are available online.
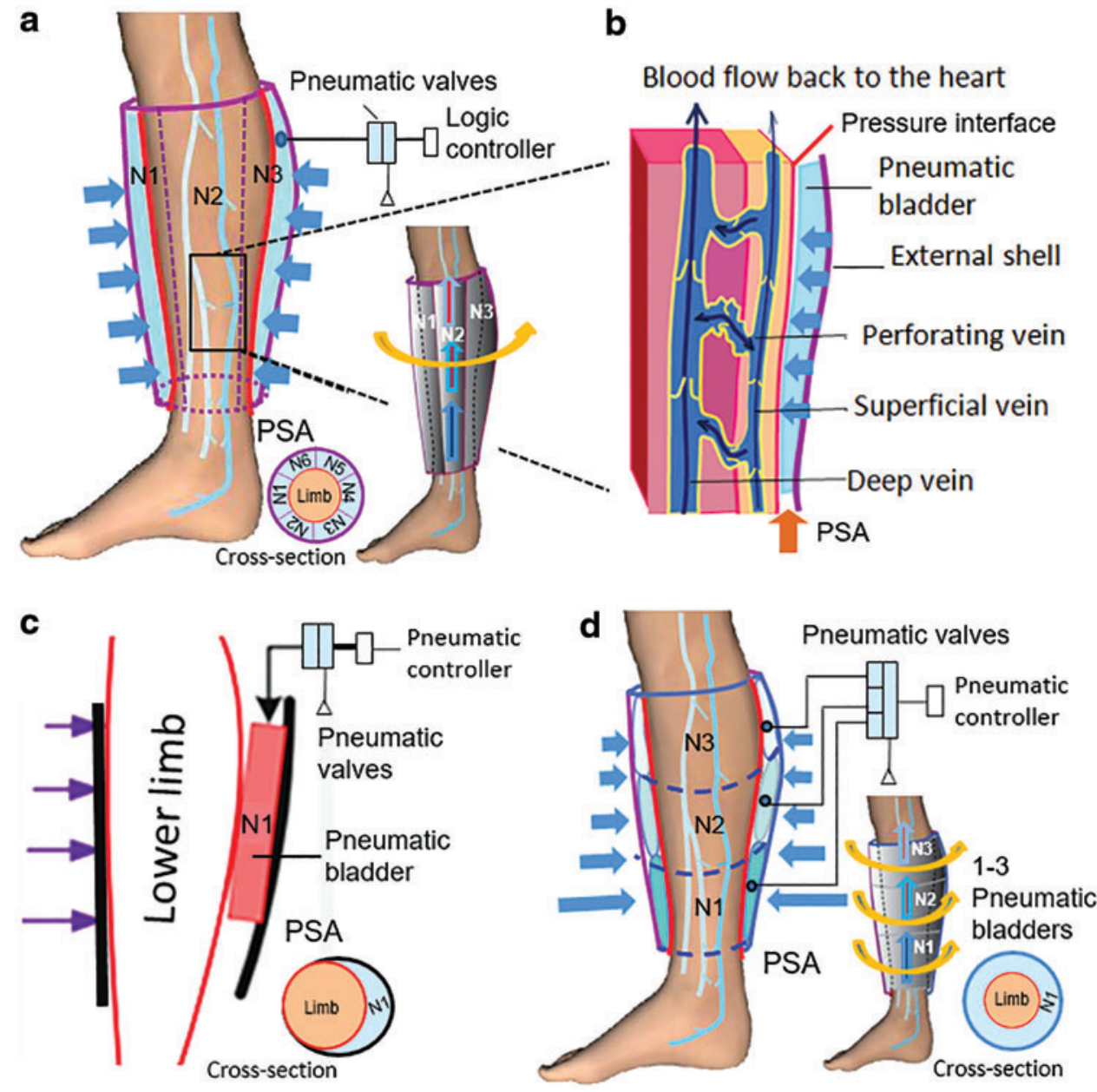
adaptable to the anatomy of the limb to minimize dead volumes that would affect the dynamic pressure function. ${ }^{54}$

Till now, the nature of intermittent compression by PSAs and the sophistic interaction with body system remain not fully understood, and its mechanical model has not been theoretically characterized.

Therefore, the purpose of this study was to explore interactive working mechanisms between PSAs and lower limbs through a mixed methodology of establishing fluidstructure coupling models, an intermittent pneumatic compression (IPC) testing system, and conducting experimental validation, to enhance understanding of PSA-lower limb system. The developed IPC testing system consisted of a PSA unit (multichambered pneumatic bladders laminated with an external textile shell), a pneumatic controller with a constant flow pump, various real-time pressure monitoring sensors, and accessory elements (air tubes and valves).

Essential factors influencing interactions between PSAs and lower limbs were characterized based on the integrative coupling model and experimental study. The essential factors included (1) pneumatic air mass flow governed by a pump controller, (2) initial thickness and stiffness of PSAs, (3) stiffness of soft tissues, and (4) contact surface area between a PSA and lower limb. The effects of each essential factor on mechanical performance of PSA were analyzed; and the simulation results of the coupling model were further validated against the data collected by the built IPC testing system. This study integrated theoretical models and experimental validation to provide an evidence-based guidance for ergonomic design and engineering of dynamic compression therapeutic devices, and laid a foundation for innovation of new pneumatic compression modalities in diverse end-uses.

\section{PSA-Lower Limb Interaction System}

\section{Configuration and mechanism analysis} of the PSA-lower limb system

Figure 2 illustrates the studied PSAs and their working condition when they were being mounted on lower limbs. Multiple inflatable air chambers (bladders) are built in the PSA, which is wrapped by an external textile shell and are supplied by a pneumatic pump system in inflation-deflation through air tubes. The interaction between a PSA and limb tissue is a complex, dynamic, and nonlinear process, as shown in Figure 3.

The pneumatic pressure $\left(p_{\mathrm{a}}\right)$ inside bladders increases with inflating (expanding) bladder powered by a pump controller. The inner wall of a bladder that contacts limb tissue generates surface contact pressure $\left(p_{\mathrm{c}}\right)$. With an increase in the pneumatic air input, $p_{\mathrm{a}}$ increases, which compresses soft tissue and results in $p_{\mathrm{c}}$, and transfers $p_{\mathrm{c}}$ from the tissue surface to a deeper venous system, finally leading to vascular deformation and blood circulation. In dynamic compression therapy, the cycled inflation and deflation of bladders produce compression waves, dynamically propagating within soft tissues to enhance a venomuscular pump and hemodynamics. Rationally controlling airflow inside bladder(s) and real-time monitoring the resultant $p_{\mathrm{a}}$ are crucial for ensuring the efficacy of pressure delivery $\left(p_{\mathrm{c}}\right)$ in a dynamic compression treatment.

\section{Fluid-structural coupling model of PSA-lower limb system}

To critically analyze multifactor interaction between a PSA and lower limb, a fluid-structural coupling model was developed. Appropriate simplification in the model is necessary to efficiently explore the key mechanisms. In this

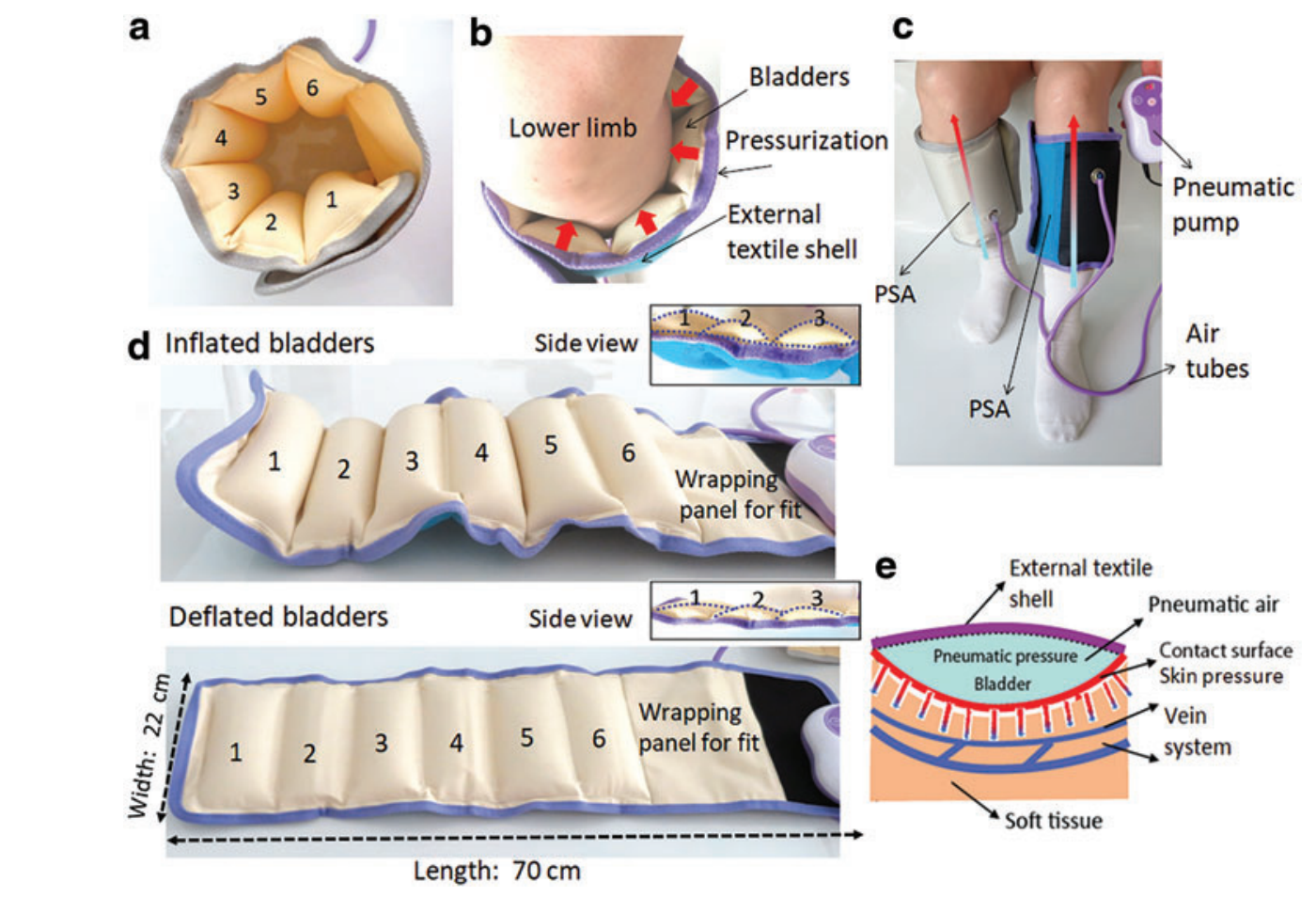

b a$$
\text { (1) }
$$
de view Wrapping
panel for $f$ (1)
FIG. 2. The studied PSAlower limb system. (a) PSA with circumferential six airtight chambers (bladders). (b) Lower limb wrapped by PSA with bladders for proactive pressure delivery. (c) Working status of PSAs in use. (d) Inflated and deflated bladders in different views. (e) Hierarchical structure of the PSA-lower limb interaction system. Color images are available online. 
FIG. 3. The interaction mechanisms of PSA-lower limb system. (a) Crosssectional view of lower limb. (b) The side cross-sectional view of interactions among external textile shell, bladder, and lower limb tissue (note: red thick line is the contact surface between bladder(s) and limb tissue). Color images are available online.

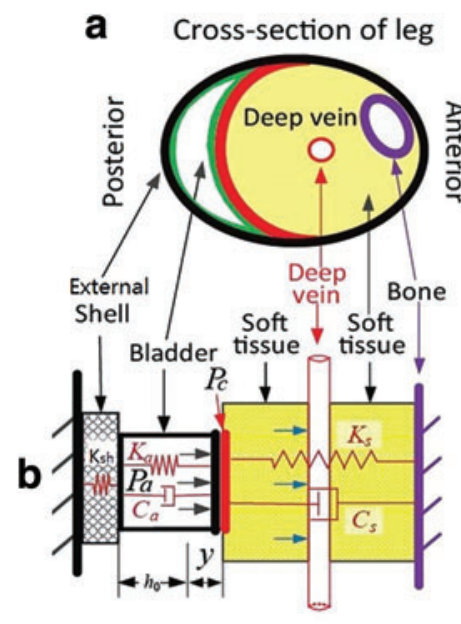

\begin{tabular}{ccc}
\hline Symbol & Unit & Physical significance \\
\hline$C_{a}$ & $\mathrm{~Pa}^{-1} \mathrm{~s}^{-1} / \mathrm{m}$ & Damping coefficient of bladder \\
\hline$C_{s}$ & $\mathrm{~Pa} \cdot \mathrm{s}^{-1} / \mathrm{m}$ & Damping coefficient of soft tissue \\
$h_{0}$ & $\mathrm{~m}$ & Initial position of bladder acting surface \\
$K_{a}$ & $\mathrm{~Pa} / \mathrm{m}$ & Stiffness of bladder, $\mathrm{Pa} / \mathrm{m}$ \\
$K_{s}$ & $\mathrm{~Pa} / \mathrm{m}$ & Stiffness of soft tissue \\
$K_{s h}$ & $\mathrm{~Pa} / \mathrm{m}$ & Stiffness of external shell \\
$K$ & $\mathrm{~Pa} / \mathrm{m}$ & Composite stiffness of bladder and external shell, \\
& & $K=\left(K_{s h} \cdot K_{s}\right) /\left(K_{s h}+K_{s}\right)$ \\
$p_{a}$ & $\mathrm{~Pa}$ & Internal pneumatic pressure of bladder \\
$p_{c}$ & $\mathrm{~Pa}$ & Contact pressure between bladder and soft tissue \\
$y$ & $\mathrm{~m}$ & Displacement of interaction surface \\
\hline
\end{tabular}

study, it is assumed that pressure transmission initiated by the PSA occurs under a quasistatic condition, where the damping effects of external textile shell, pneumatic bladder, and soft tissue are eliminated. Furthermore, no clearance was observed between the lower limb and bladder during inflation and deflation cycles, and the stiffness of soft tissue, bladder, and external shell was constant. As illustrated in Figure 3, the external shell and bladder of PSA unit as well as the soft tissue of the lower limb were in a serial connection. No displacement occurs between the laminated bladder and external shell in dynamic inflation-deflation cycles. The inflation and deflation process in the bladder obeys the ideal gas law:

$$
p_{\mathrm{a}} V_{\mathrm{a}}=Q R T
$$

where $p_{\mathrm{a}}$ is the pneumatic pressure inside a bladder; $Q$ is the pneumatic air mass flow of the bladder; $R$ represents an air constant; $T$ denotes absolute temperature; and $V_{\mathrm{a}}$ is the bladder volume.

Based on the assumptions in the "Fluid-Structural Coupling Model of PSA-Lower Limb System" section, bladder volume can be expressed as follows:

$$
V_{\mathrm{a}}=A\left(h_{0}+y\right)
$$

where $A$ is the contact area between bladder and soft tissue; $h_{0}$ is the initial thickness of the bladder; and $y$ denotes the displacement of the contact surface with positive and negative values responding to inflation and deflation processes. By substituting Equation (2) into Equation (1), an expression of $\dot{p}_{\mathrm{a}}$ is obtained as follows:

$$
\dot{p}_{\mathrm{a}}=\frac{\left(R T Q-p_{\mathrm{a}} A \dot{y}\right)}{A\left(h_{0}+y\right)}
$$

The pressure at the left side of contact surface (red line in Fig. 3b) can be expressed as follows:

$$
p_{\mathrm{c}}=p_{\mathrm{a}}-K y-C_{\mathrm{a}} \dot{y}
$$

where $p_{\mathrm{a}}$ is the internal pneumatic pressure of the bladder; $y$ is displacement of the contact surface; $C_{\mathrm{a}}$ indicates the damping coefficient of bladder and is mainly determined by bladder materials and structures; $\dot{y}$ denotes the moving velocity of the contact surface; and $K$ is the composite stiffness of external textile shell and bladder. Considering the serial connection structure, $K$ can be illustrated as follows:

$$
K=\frac{K_{\mathrm{sh}} K_{\mathrm{a}}}{K_{\mathrm{sh}}+K_{\mathrm{a}}}
$$

where $K_{\text {sh }}$ varies with the shell thickness and material properties, and $K_{\mathrm{a}}$ varies with the bladder structure and material property.

The pressure at the right side of contact surface (red line in Fig. 3b) can be expressed as follows:

$$
p_{\mathrm{c}}=K_{\mathrm{s}} y+C_{\mathrm{s}} \dot{y}
$$

By combining Equations (3-6), the control function of the PSA-lower limb interaction system is established as follows:

$$
\left\{\begin{array}{l}
\dot{p}_{\mathrm{a}}=\frac{\left(R T Q-p_{\mathrm{a}} A \dot{y}\right)}{A\left(h_{0}+y\right)} \\
p_{\mathrm{c}}=p_{\mathrm{a}}-K y-C_{\mathrm{a}} \dot{y} \\
y=\frac{p_{\mathrm{c}}-C_{\mathrm{s}} \dot{y}}{K_{\mathrm{s}}} \\
\frac{1}{K}=\frac{1}{K_{\mathrm{sh}}}+\frac{1}{K_{\mathrm{a}}}
\end{array}\right.
$$

The fluid-structural coupling model [Eq. (7)] is an implicit differential equation group reflecting the fluid-structural coupling mechanism and illustrates the relationship among the aforementioned key factors, including the bladder pneumatic pressure $\left(p_{\mathrm{a}}\right)$, contact surface displacement $(y)$, moving velocity of contact surface $(\dot{y})$, and the contact pressure $\left(p_{\mathrm{c}}\right)$ between the bladder and soft tissue. Equation (7) can be solved using ODE $15 \mathrm{i}$ in MATLAB once the air mass flow $Q$ is obtained. $Q$ can be calculated using the ISO 6358 Standard and experimental data obtained in the "Pneumatic Air Mass Flow Calculation', section.

\section{Pneumatic air mass flow calculation}

The pneumatic air mass flow $(Q)$ critically determines both $p_{\mathrm{a}}$ and $p_{\mathrm{c}}$. Figure 4 illustrates the testing setting of $Q$ in inflation and deflation processes. An orifice valve was installed along the air supply channel. The pneumatic pressures recorded before and after the orifice valve are denoted by $p_{1}$ and $p_{2}$, respectively. 
a

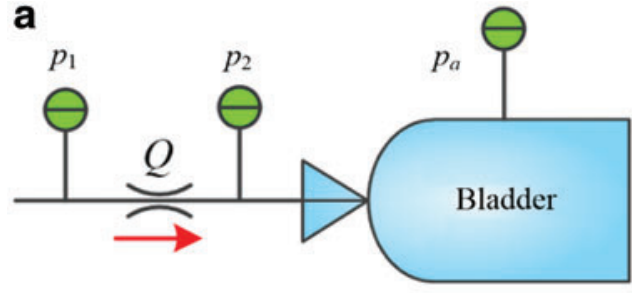

b Charge process

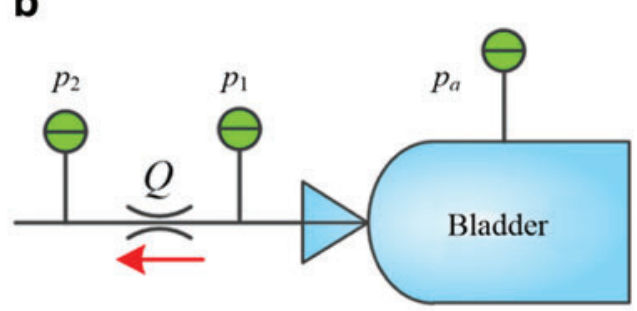

Discharge process

FIG. 4. Schematic configuration of the test setting of air mass flow rate $(Q)$ in (a) inflation (charge process) and (b) deflation (discharge process). Color images are available online.

It is assumed that the temperature inside the bladder during the inflation-deflation cycle is constant and isothermal, and the supplied air by the pneumatic pump is ideal gas, which obeys the ideal gas state equation. With this assumption, the pneumatic air mass flow $Q$ can be calculated through Equation (8), ${ }^{55}$

$$
Q=C \rho_{0} p_{1} K_{\mathrm{T}}\left[1-\left(\frac{\frac{p_{2}}{p_{1}}-b}{1-b}\right)^{2}\right]^{m}
$$

where $C$ is the sonic conductance; $\rho_{0}$ is the mass density of air under standard reference atmosphere $\left(1.29 \mathrm{~kg} / \mathrm{m}^{3}\right) ; p_{1}$ is the upstream stagnation pressure; $p_{2}$ is the downstream pressure; $K_{\mathrm{T}}$ is the air temperature coefficient; $b$ is the critical back-pressure ratio; and $m$ is the subsonic index. The sonic conductance $C\left(\mathrm{~m}^{3} /(\mathrm{s} \mathrm{Pa})\right)$ can be derived from Equation (9). ${ }^{56}$

$$
C=\frac{\pi d^{3}}{20} \frac{1}{\sqrt{\frac{20 L}{d^{1.31}}+1}}
$$

where $d$ is the diameter of the valve orifice, and $L$ represents the length of the valve orifice. To calculate the air mass flow $Q$, the critical back pressure ratio $b$ and subsonic index $m$ are calculated first in terms of Equation (8). The conductance ratio is defined as follows:

$$
y_{i}=\frac{C_{\mathrm{e}}}{C}
$$

subject to

$$
C_{\mathrm{e}}= \pm \frac{V_{\mathrm{a}}}{\rho_{0} p_{1} R \sqrt{T_{0} T_{\mathrm{a}}}} \frac{d p_{\mathrm{a}}}{d t}
$$

where $V_{\mathrm{a}}$ is the bladder volume, which is calculated by $A\left(h_{0}+y\right) ; T_{0}$ and $T_{\mathrm{a}}$ are the absolute temperature at standard reference atmosphere and absolute temperature inside the bladder at the start of deflation; "+" represents the inflation process, whereas "-_" indicates the deflation process.

To determine $b$ and $m$, the least-square method was used. By inputting the values of arbitrary $b$ and $m$ in Equation (12), the difference can be calculated as follows:

$$
\delta_{i}=y_{i}-\left[1-\left(\frac{x_{i}-b}{1-b}\right)^{2}\right]^{m}
$$

Then, the least squared difference $E$ can be obtained as follows:

$$
\begin{aligned}
E=\sum_{i=1}^{n} \delta_{i}^{2} & =\left\{y_{1}-\left[1-\left(\frac{x_{1}-b}{1-b}\right)^{2}\right]^{m}\right\}^{2} \\
& +\left\{y_{2}-\left[1-\left(\frac{x_{2}-b}{1-b}\right)^{2}\right]^{m}\right\}^{2} \\
& +\cdots+\left\{y_{n}-\left[1-\left(\frac{x_{n}-b}{1-b}\right)^{2}\right]^{m}\right\}^{2}
\end{aligned}
$$

Figure 5 summarizes a flow chart to calculate parameters $b$ and $m$. The sonic conductance $C$ can be calculated using Equation (9) according to the bladder structural property. The conductance $C_{\mathrm{e}}$ is obtained based on the experimental pressure variation in a time domain using Equation (11). The initial values of both $b$ and $m$ are assumed as $0.5,{ }^{55}$ which are adjusted by $E$ as illustrated in Equation (13). The values of $b$ and $m$ are determined once the minimum value of $E$ is obtained. And then, the air mass flow $(Q)$ can be further calculated by inputting $b$ and $m$ into Equation (8). Finally, all the physical parameters involved in the IPC system can be obtained by Equation (7) in the "Fluid-Structural Coupling Model of PSA-Lower Limb System" section, which is validated against experimental data in the "Model Validation" section.

\section{Experimental Setup}

\section{Configuration of the PSA-lower limb testing system}

Based on the aforementioned mechanism analysis, an IPC testing system was designed (Fig. 6a) for two purposes: (1) acquire pneumatic pressures $\left(p_{1}, p_{2}\right)$ and intermediate parameters $(b, m)$ as described in the "Pneumatic Air Mass Flow Calculation" section, to obtain $Q$; and (2) validate the fluid-structural coupling model constructed in the "FluidStructural Coupling Model of PSA-Lower Limb System" section. The IPC testing system comprises a PSA unit with six circumferential bladders (Fig. 2a) around an artificial lower limb, a data acquisition board with three real-time air pressure monitoring sensors, and a laptop displaying and recording the collected pressure signal data.

Figure $6 \mathrm{~b}$ illustrates an operational IPC testing system, in which an artificial lower limb in a cylinder shape was fabricated using three-dimensional printing technology and soft 


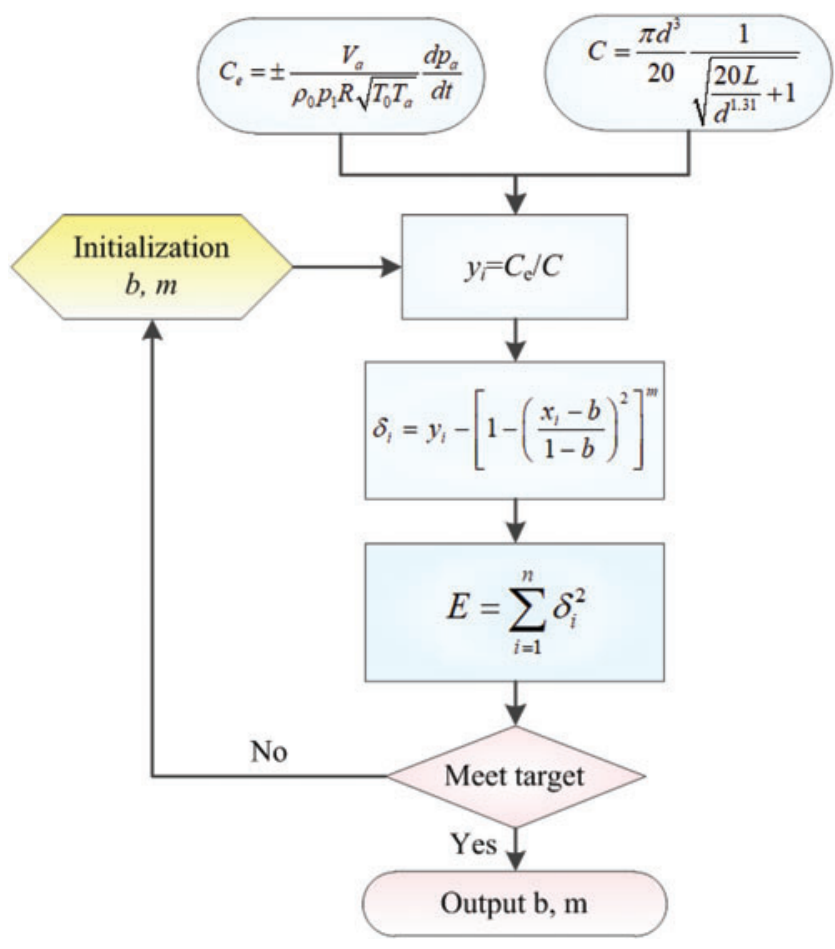

FIG. 5. A flow chart to calculate parameters $b$ and $m$. Color images are available online.

gel materials. The morphology and internal geometric structure of the limb model were based on magnetic resonance imaging scanning and three-dimensional digital body scanning on a healthy female subject's lower limb. The diameter, length, and shore hardness of the limb model were $110 \mathrm{~mm}, 200 \mathrm{~mm}$, and $5 \mathrm{HA}$, respectively. Two viscoelastic tubes (red) simulating superficial and deep veins were set at periphery and near center to form a more realistic lower limb model.

The PSA unit is regarded as the core of the developed IPC testing system and delivers a controllable pressure dosage to the lower limb. A 5-mm-diameter air inlet was set at the bladder shell of the PSA unit to allow pneumatic air supplied by the pneumatic pump to fill in the bladder. Three differential pressure sensors in type of MPX5100DP applied in the IPC testing system are piezoresistive transducers made by monolithic silicon (Freescale Semiconductor, Inc., Austin, TX). Their pressure testing range is $0-100 \mathrm{kPa}$, error range is $2.5 \%$ maximum error over $0^{\circ} \mathrm{C}$ to $85^{\circ} \mathrm{C}$, and the accuracy, sensitivity, and response time are $\pm 2.5 \% \mathrm{~V}_{\mathrm{FSS}}$, $45 \mathrm{mV} / \mathrm{kPa}$, and $1.0 \mathrm{~ms}$, respectively.

The applied differential pressure sensors were sequentially connected with the air inlet tubes using tee joints (Fig. 6c), in which pressure sensors (1) and (2) were used to test the input pneumatic pressures $p_{1}$ and $p_{2}$ before and after the orifice, the valve 9, and pressure sensor (3) was used to detect pneumatic pressure $p_{\mathrm{a}}$ inside the bladder. The $1 \mathrm{~mm}$ diameter and $10 \mathrm{~mm}$ length of the orifice valve can be used to calculate sonic conductance $C$ in terms of Equation (3). The difference between pneumatic pressures $p_{1}$ and $p_{2}$ detected by the orifice valve was used to determine the pneumatic air mass flow $Q$ in terms of Equation (8).

The pneumatic pressure signals collected from the aforementioned three differential pressure sensors were transmitted to the data acquisition card, which was installed with an analog to digital converter (AD7606) and data processing unit. The time domain signal was displayed on the screen of the laptop for real-time analysis. The contact pressure $\left(p_{\mathrm{c}}\right)$ between the PSA and the lower limb was tested using a piezoresistive sensor [Yubo intelligent technology (Hangzhou) Co. Ltd].

To reduce the influence of PSA setup procedure on the testing results, at the initial condition, the PSA unit was appropriately wrapped around the lower limb to conform to the limb circumference avoiding excessively squeezing or existing clearance between the bladder and the lower limb. Before data collection, several cycles of inflation and deflation of PSA unit were performed to allow the testing condition to be more reliable. In general, the initial pressure values were slightly higher owing to the uneven thrusts and frictions existing between the bladder and the lower limb. After several cycles of operation (i.e., three or four cycles), the pressure values became more stable and the effective data were collected to characterize the pressure variations.

The working modes (i.e., inflation-holding-deflation cycle) and control logic were governed by the air pump controller of the IPC testing system. Different compression cycles are applied in the IPC treatment in practice depending on the individuals' requirements. In this study, a mode of $20-10-8 \mathrm{~s}$ in one cycle sustaining $38 \mathrm{~s}$ was adopted as an example, which is a recommended treatment cycle by a commercial IPC device for daily home care of the lower limbs. This treatment cycle included three stages, that is, (1) inflation in the first $20 \mathrm{~s}$, where the pneumatic pump controller initiates and charges the bladder with a constant pneumatic air mass flow; (2) holding from 21 to $30 \mathrm{~s}$, where the solenoid valve closes to maintain pneumatic pressure inside bladder for $10 \mathrm{~s}$; and (3) deflation in the last $8 \mathrm{~s}$, where the solenoid valve opens to deflate.

\section{System testing method}

Pneumatic pressure $\left(p_{\mathrm{a}}\right)$ variation can be used to determine the pneumatic air mass flow under a certain inflationdeflation cycle, and to analyze the corresponding mechanism of the design parameter on PSA performance. The $p_{\mathrm{a}}$ variation can also be used to validate the established fluid-structural coupling model. Figure 7 depicts an example of the detected periodic working rhythms of the PSA using the three aforementioned pressure sensors (Fig. 6c). The variation profile and amplitude of $p_{\mathrm{a}}$ were governed by the pneumatic pump controller and solenoid valve. This profile was displayed real time on the screen of the laptop in the developed IPC testing system.

\section{Model Validation}

To validate the developed fluid-structural coupling model, the simulated and the experimental data are compared. Table 1 lists the physical parameters used in the developed coupling model.

The values of the pneumatic conductance $(C)$ and contact area $(A)$ are calculated using Equation 9 and the formula $A=2 \pi r L$ (Table 1), respectively. The values of air constant, air density, and temperature are constant. The critical backpressure ratio $(b)$ and subsonic index $(m)$ can be obtained by 


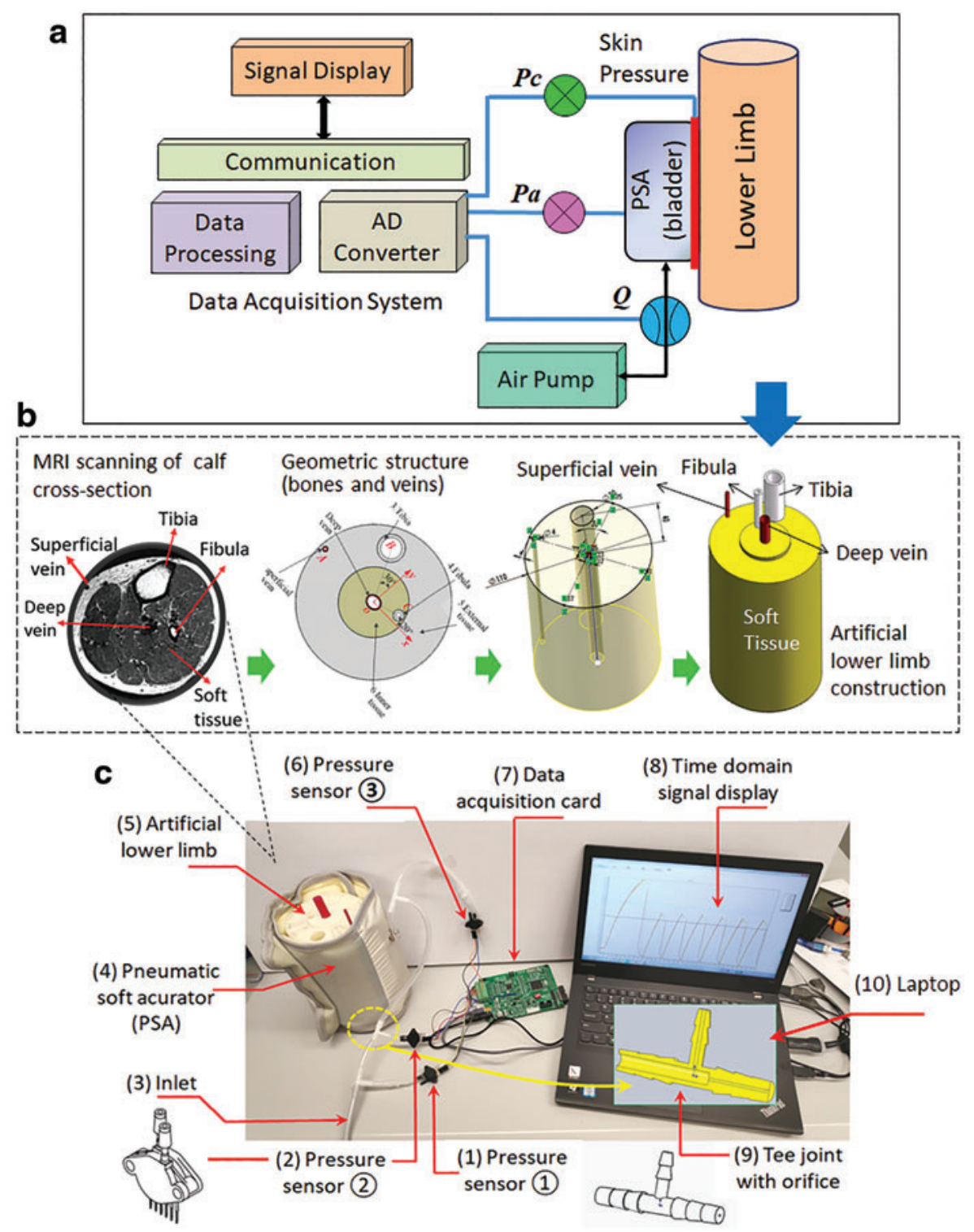

FIG. 6. IPC testing system design and construction. (a) Schematic diagram of the developed IPC testing system. (b) Engineering of an artificial lower limb model based on magnetic resonance scanning. (c) Experimental setup and testing components involved in the IPC testing system. IPC, intermittent pneumatic compression. Color images are available online.

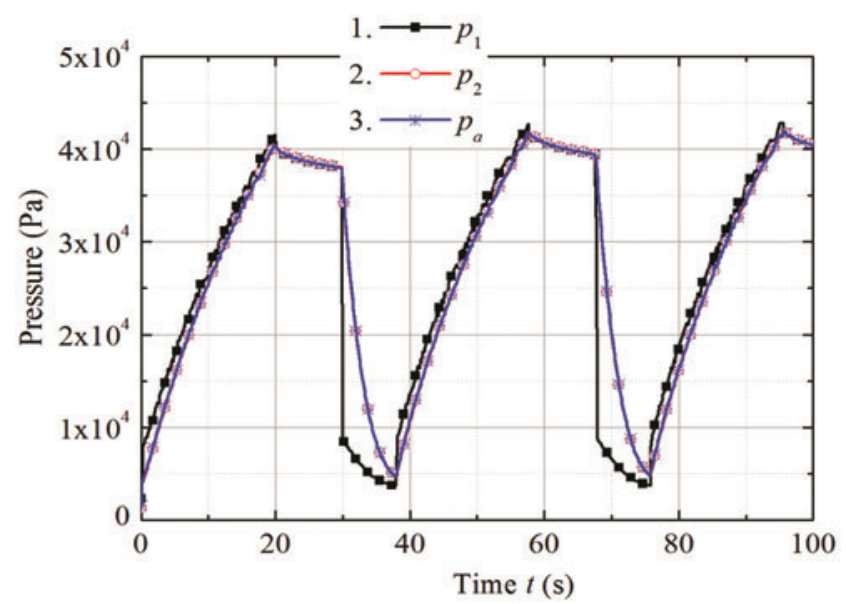

FIG. 7. Detected pneumatic pressure in inflation-holdingdeflation cycles by IPC testing system. Color images are available online. calculation or by experimental test following the process illustrated in Figure 5.

The initial thickness of the bladder $h_{0}$ is tested using the Vernier caliper (Mitutoyo $150 \mathrm{~mm}$ Digital Caliper, resolution $0.01 \mathrm{~mm}$, accuracy $\pm 0.02 \mathrm{~mm}$; Kawasaki, Japan). The external shell stiffness $K_{\text {sh }}$ can be determined by the experimental test as shown in the Supplementary Data (Supplementary Fig. S1). The stiffnesses of bladder and soft tissue can be determined from the reference. ${ }^{56}$ The damping effects of both bladder and soft tissue are eliminated in the calculation, and hence, the bladder damping coefficient $C_{\mathrm{a}}$ and soft tissue damping coefficient $C_{\mathrm{s}}$ are $0 \mathrm{~N} \bullet \mathrm{s} / \mathrm{m}$, respectively. The inflation time, holding time, and deflation time are determined as 20,10, and $8 \mathrm{~s}$, respectively, which can be controlled by the pneumatic pump in the experiment of this study.

The simulation process using the coupling model to calculate physical parameters [e.g., pneumatic pressure $\left(p_{\mathrm{a}}\right)$, contact pressure $\left(p_{c}\right)$, and contact surface displacement $\left.(y)\right]$ is presented as follows: 


\begin{tabular}{|c|c|}
\hline Step 1 & $\begin{array}{l}\text { Calculate sonic conductance }(C) \text { based on } \\
\text { orifice structural parameters using Eq. (9) } \\
(\text { e.g., diameter }(d) \text { and length }(L)) \text {. }\end{array}$ \\
\hline Step 2 & $\begin{array}{l}\text { Test and calculate conductance } C_{\mathrm{e}} \text { based on } \\
\text { Eq. (11); } C_{\mathrm{e}} \text { in time-domain is presented } \\
\text { in Figure } 8 \mathrm{a} \text { and b. }\end{array}$ \\
\hline Step 3 & $\begin{array}{l}\text { Calculate intermediate parameters } b \text { and } m \\
\text { using Eq. (13). }\end{array}$ \\
\hline Step 4 & $\begin{array}{l}\text { Substitute the calculated sonic conductance } \\
(C) \text {, critical back-pressure ratio }(b) \text {, and } \\
\text { subsonic index }(m) \text { to Eq. }(8) \text { to acquire } \\
\text { pneumatic air mass flow } Q \text {. }\end{array}$ \\
\hline Step 5 & $\begin{array}{l}\text { Substitute the pneumatic air mass flow } Q \text { and } \\
\text { parameters in Table } 1 \text { to Eq. }(7) \text {, to obtain } \\
\text { the key parameter values of the bladder } \\
\text { pressure }\left(p_{\text {a }}\right) \text {, surface contact pressure } \\
\left(p_{\mathrm{c}}\right) \text {, and contact surface displacement }(y) \text {. }\end{array}$ \\
\hline
\end{tabular}

Figure 9a indicates a favorable agreement between the simulated and the experimental results, which demonstrates an applicability of the developed coupling model in prediction of the pneumatic pressure $\left(p_{\mathrm{a}}\right)$ and its variation in inflationdeflation cycles of the PSA unit. The results calculated by the coupling model can be used to devise novel PSA designs for effective pressure delivery. The quantized error values of the pneumatic pressure $p_{\mathrm{a}}$ are shown in Figure $9 \mathrm{~b}$.

The difference between the simulated and the experimental data could have been caused by elimination of the damping effects of both bladders and soft tissues in the coupling model, as well as the impact of the dynamic stiffness variation of bladders during the inflation-holding-deflation cycles in practice. In the simulation modeling, the stiffness of $K_{\mathrm{sh}}$ (shell), $K_{\mathrm{a}}$ (bladder), and $K_{\mathrm{s}}$ (soft tissue) is assumed to be constant, while the practical stiffness of these three parameters is nonlinearly varying during the deflation process, which is the potential reason for sudden rise of relative errors in the deflation stage. Referring to the related studies, ${ }^{57,58}$ the relative errors less than $15 \%$ at the holding process are acceptable from an engineering perspective.

\section{Results and Discussion}

Figure 10a-f illustrates interactions among key parameters involved in the PSA-lower limb system. Effects of multiple factors (e.g., stiffness of bladder and external textile shell, stiffness of soft tissues, air mass flow, and contact area) on pneumatic pressure inside the bladder, contact surface pressure, and contact surface displacement are quantitatively analyzed based on the simulated and experimental results.

\section{Effect of stiffness of the bladder and external shell}

Figure 10a illustrates the stiffness effects of the external textile shell $\left(K_{\mathrm{sh}}\right)$ and bladder $\left(K_{\mathrm{a}}\right)$ on pneumatic pressure $\left(p_{\mathrm{a}}\right)$ inside the bladder, surface contact pressures $\left(p_{\mathrm{c}}\right)$, and contact surface displacement $(y)$ in the inflation process $(0-$ $20 \mathrm{~s})$. With increase in the pneumatic air in the bladder, both $p_{\mathrm{a}}$ and $p_{\mathrm{c}}$ increased. Bladder and external shell stiffness is largely influenced by material elastic moduli, bending rigidity, and thickness.

When stiffness $\left(K_{\mathrm{sh}}\right.$ and $\left.K_{\mathrm{a}}\right)$ was low $\left(10^{5} \mathrm{~Pa} / \mathrm{m}\right)$, the bladder and shell were relatively thin and soft, which generated lower elastic potential energy in the pneumatic bladder. Consistent results were shown in the simulated and tested $p_{\mathrm{c}}$ and $p_{\mathrm{a}}$. When stiffness $\left(K_{\mathrm{sh}}\right.$ and $\left.K_{\mathrm{a}}\right)$ was high $\left(10^{7} \mathrm{~Pa} / \mathrm{m}\right)$, the bladder and shell were relatively thick and stiff, which induced high elastic potential energy to be stored in the bladder and textile shell. This results in the difference between the simulated and tested $p_{\mathrm{a}}$ and $p_{\mathrm{c}}$, which increased with inflation time, especially at the later stage. The results indicated that the bladder and external shell with higher stiffness could simultaneously augment $p_{\mathrm{c}}$ and $p_{\mathrm{a}}$, and $p_{\mathrm{a}}$ increased more rapidly than $p_{\mathrm{c}}$.

Figure $10 \mathrm{~b}$ illustrates varying contact surface displacement $y$ with variation of stiffness $K_{\mathrm{a}}$ and $K_{\mathrm{sh}}$. Here, $y$ increased with inflation, demonstrated increased expansion of bladder, and resultant increased contact pressure at limb tissues. However, with the increase in bladder and shell stiffness, the contact surface displacement decreased with constant input of pneumatic air, which limited the volume expansion and deformation of the bladder, and reduced surface contact pressure $p_{\mathrm{c}}$.

Table 1. Physical Parameters Used in Fluid-Structural Coupling Model

\begin{tabular}{lll}
\hline Parameters & \multicolumn{1}{c}{ Value } & Notes \\
\hline Pneumatic conductance, $C$ & $3.8061 \times 10^{-12} \mathrm{~m}^{3} /(\mathrm{s} \bullet \mathrm{Pa})$ & Calculation [Eq. $(9)]$ \\
Contact area, $A(A=2 \pi r L)$ & $0.069 \mathrm{~m}^{2}$ & Calculation \\
Air constant, $R$ & $8.314 \mathrm{~J} /(\mathrm{mol} \bullet \mathrm{K})$ & Constant \\
Air density, $\rho_{0}$ & $1.29 \mathrm{~kg} / \mathrm{m}^{3}$ & Constant \\
Temperature, $T$ and $T_{\mathrm{a}}$ & $293 \mathrm{~K}$ & Constant \\
Critical back-pressure ratio, $b$ & $0.28($ inflation $)$ & Test and calculation \\
& $9.35($ deflation $)$ & Test and calculation \\
Subsonic index, $m$ & $0.68($ inflation $)$ & Test and calculation \\
& $10(\mathrm{deflation})$ & Test and calculation \\
Initial thickness of bladder, $h_{0}$ & $0.01 \mathrm{~m}$ & Experimental \\
External shell stiffness, $K_{\mathrm{sh}}$ & $5 \times 10^{5} \mathrm{~Pa} / \mathrm{m}$ & Experimental \\
Bladder stiffness, $K_{\mathrm{a}}$ & $5 \times 10^{5} \mathrm{~Pa} / \mathrm{m}$ & Yang et al. ${ }^{56}$ \\
Soft tissue stiffness, $K_{\mathrm{s}}$ & $7 \times 10^{6} \mathrm{~Pa} / \mathrm{m}$ & Yang et al. ${ }^{56}$ \\
Bladder damping coefficient, $C_{\mathrm{a}}$ & $0 \mathrm{~N} \bullet \mathrm{s} / \mathrm{m}$ & Assumption \\
Soft tissue damping coefficient, $C_{\mathrm{s}}$ & $0 \mathrm{~N} \bullet \mathrm{s} / \mathrm{m}$ & Assumption \\
Inflation time & $20 \mathrm{~s}$ & Experimental \\
Pressure holding time & $10 \mathrm{~s}$ & Experimental \\
Deflation time & $8 \mathrm{~s}$ & Experimental
\end{tabular}



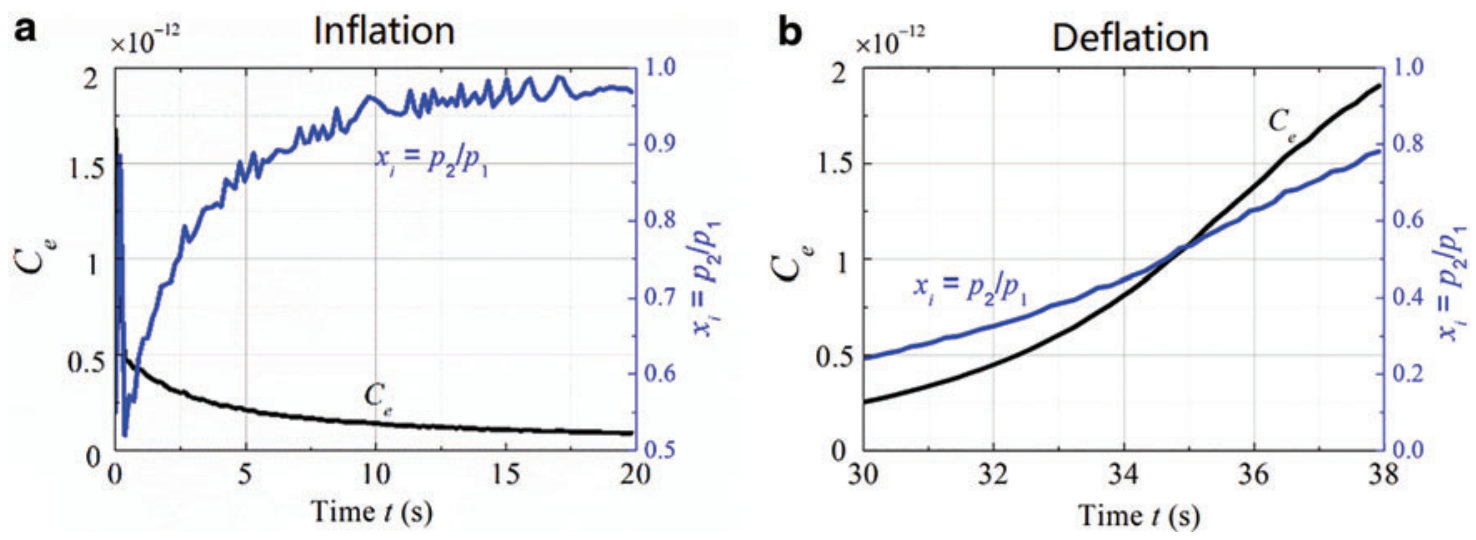

FIG. 8. Intermediate parameters $C_{e}$ and $x_{i}$ resulting from the calculation process of (a) inflation and (b) deflection processes. Color images are available online.

\section{Effect of stiffness of limb tissues}

Figure 10c illustrates the effects of stiffness of limb tissues on pneumatic pressure $\left(p_{\mathrm{a}}\right)$, contact pressure $\left(p_{\mathrm{c}}\right)$, and contact surface displacement $(y)$. With the increase in tissue stiffness, both $p_{\mathrm{c}}$ and $p_{\mathrm{a}}$ increased with inflation, whereas their differences decreased gradually. Here, $y$ decreased with time, which indicated that the stiffer tissue would counteract
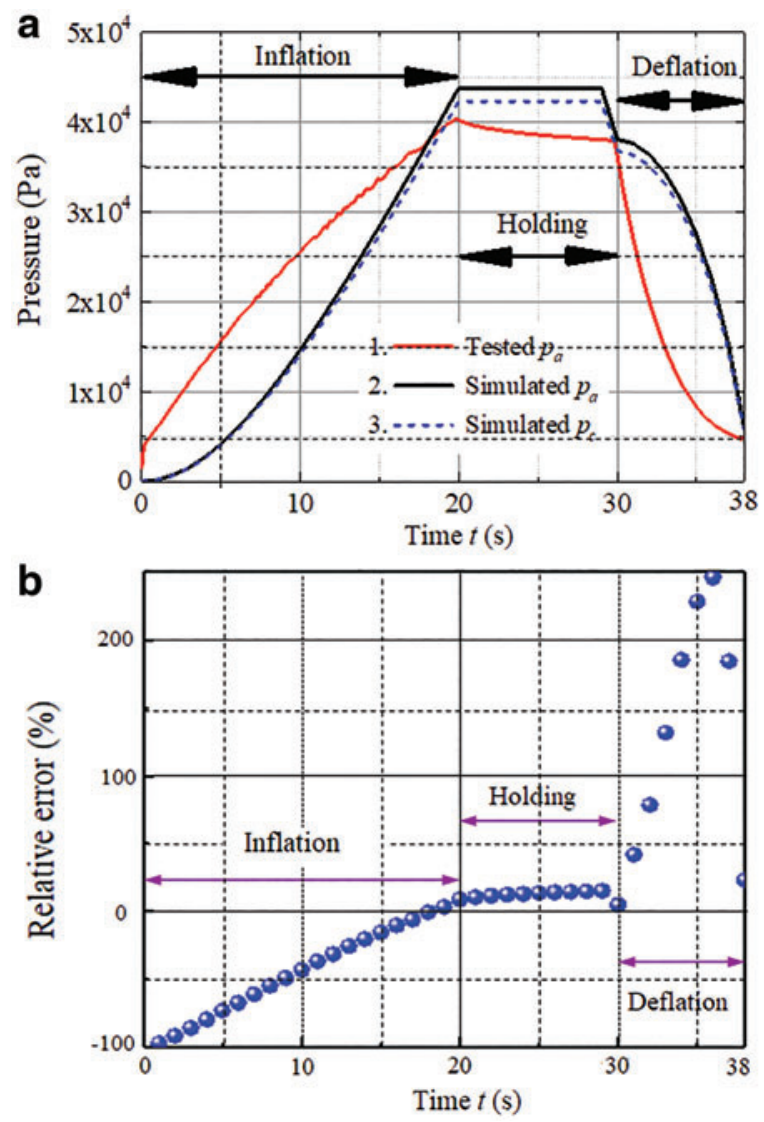

FIG. 9. (a) Comparison on pneumatic pressure between the simulated and tested results in one compression cycle. (b) The quantized relative errors of pneumatic pressure at the three stages of one compression cycle. Color images are available online. volume expansion of the bladder during inflation. Thus, the lower limb with stiffer tissue would generate higher pressure dosage $\left(p_{\mathrm{a}}\right)$ than that with softer tissues, which implied that pressure treatment effects maybe varied among various endusers with different tissue properties (e.g., young adults or older adults, or athletes or nonathletes). Therefore, a customized PSA should be used, and the customized design should reflect users' biological and anatomic characteristics.

\section{Effect of contact surface area}

Figure 10d illustrates the variation of the contact area of the bladder with tissue surface under a constant air mass flow $(Q)$ input and initial thickness of bladder $\left(h_{0}\right)$. The contact surface area largely depends on the morphology of the PSA design. The increased bladder size of the PSA unit increased the contact area $(A)$ between the bladder and lower limb.

The simulated results indicated that with increase in the bladder size, the surface contact pressure $p_{\mathrm{c}}$, the pneumatic pressure inside bladder $p_{\mathrm{a}}$ and the contact surface displacement $y$ decrease, which indicated that when the inflation capability of the air pump controller was determined, the morphologic design of the pneumatic bladder would directly influence the pneumatic pressure inside the bladder, interface pressure contacting with soft tissues, and bladder volume. For example, when the air pump size was fixed, the increased bladder size (i.e., surface contact area) would result in insufficient pressure dosages delivered to the affected lower limb, which can negatively influence compression therapeutic effects in practical treatment.

\section{Effect of the initial thickness of the bladder}

Figure 10e depicts the effects of the initial thickness of the bladder $\left(h_{0}\right)$ on the contact surface pressure $p_{\mathrm{c}}$, pneumatic pressure $p_{\mathrm{a}}$, and contact surface displacement $y$. Here, $h_{0}$ is a sensitive indicator that reflects the initial volume of the bladder. Lower $h_{0}$ implies a smaller bladder volume, which would be inflated more rapidly to deliver pressure dosages to the target tissue zone; whereas higher $h_{0}$ would increase the bladder volume, which could require longer inflation time to fill the bladder chamber, thus delaying pressure achievement. In terms of Equation (1), when air mass flow $Q$, air constant $R$, and temperature $T$ are constant, the enlarged bladder volume can be only equilibrated by a reduced initial pressure $p_{\mathrm{a}}$. When $h_{0}$ increased, the $p_{\mathrm{a}}, p_{\mathrm{c}}$, and $y$ are decreased, 

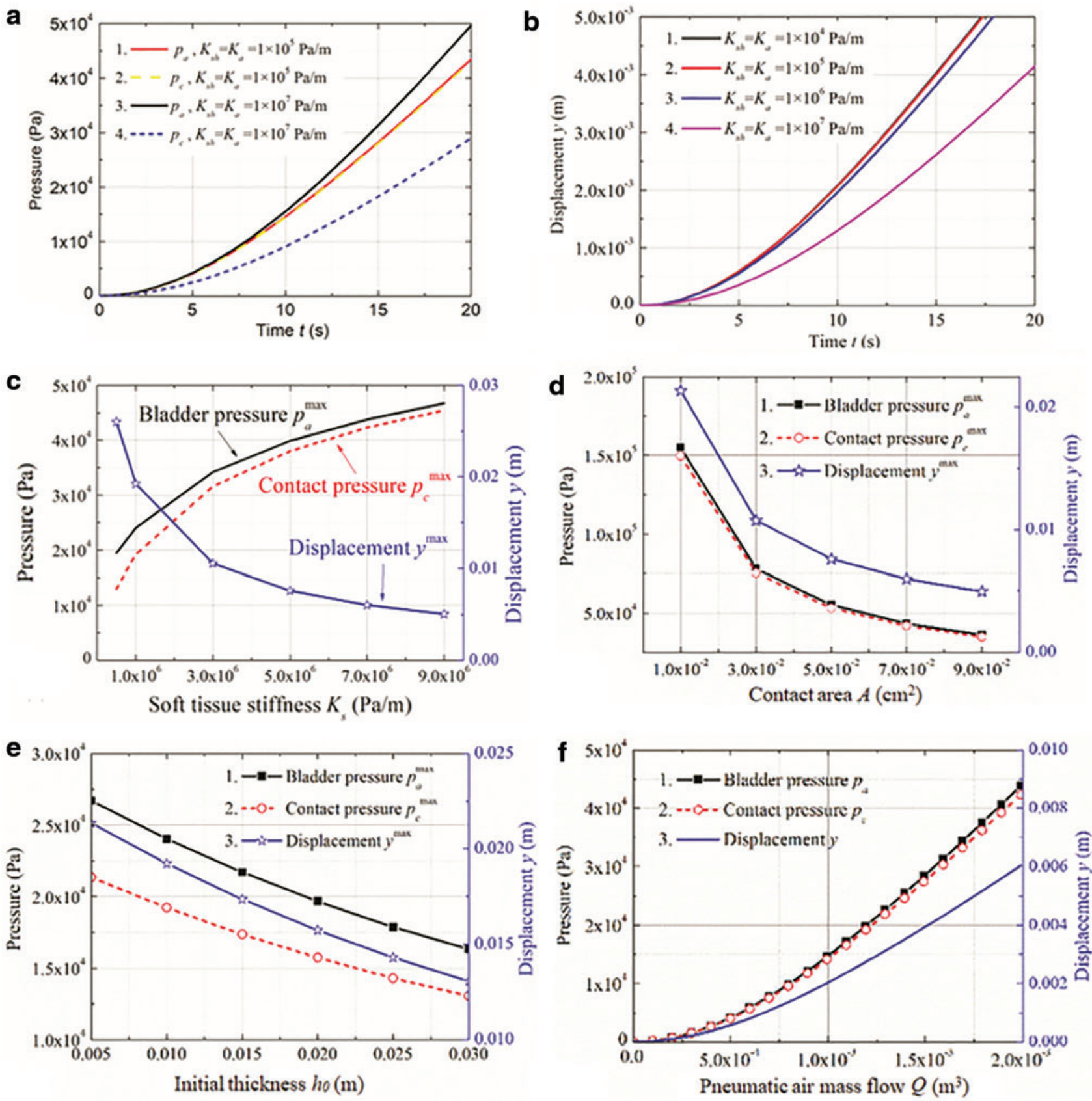

FIG. 10. Effect of stiffness $K_{\mathrm{sh}}$ and $K_{\mathrm{a}}$ on (a) surface pressure contact $p_{\mathrm{c}}$ and pneumatic pressure inside bladder $p_{\mathrm{a}}$, and on (b) contact surface displacement $y$. (c) Effects of soft tissue stiffness $K_{\mathrm{s}}$ on $p_{\mathrm{c}}, p_{\mathrm{a}}$, and $y$. (d) Effects of contact area $A$ on $p_{\mathrm{c}}$, $p_{\mathrm{a}}$, and $y$. (e) Effects of bladder initial thickness $h_{0}\left(K_{\mathrm{s}}=1 \times 106 \mathrm{~Pa} / \mathrm{m}\right)$ on $p_{\mathrm{c}}, p_{\mathrm{a}}$, and $y$. (f) Effects of pneumatic air mass flow $Q$ on $p_{\mathrm{c}}, p_{\mathrm{a}}$, and $y$. Color images are available online.

which is consistent with the modeling analysis in terms of Equation (7).

\section{Effect of the pneumatic air mass flow}

The pneumatic air mass flow $Q$ is one of the most crucial parameters, which directly determines pressure dosage delivered in dynamic compression therapy. Figure $10 \mathrm{f}$ indicates that pneumatic pressure $p_{\mathrm{a}}$ and contact pressure $p_{\mathrm{c}}$ nonlinearly increase with the increase in the air mass flow $Q$ (e.g., from 0 to $\left.4.5 \times 10^{4} \mathrm{~Pa}\right)$. The contact surface displacement $y$ increases from 0 to $6 \mathrm{~mm}$ with increase in $Q$ from 0 to $2 \times 10^{-3} \mathrm{~m}^{3}$. The varying curves and interactions of each studied parameter would provide an important reference for designers and engineers in PSA design and application, including bladder materials and pump controller selection, dimensional determination, and end-user target.

\section{Conclusion and Remarks}

In this study, we established a fluid-structural coupling model and an IPC testing system to analyze interactions 
between PSAs and lower limb, and to discuss factors that influence characteristics of PSAs in dynamic pressure delivery.

The developed coupling model demonstrated a favorable agreement with the experimental data, which indicated its applicability in predicting effects of varying parameter designs of a PSA on pneumatic air pressure, skin pressure dosage, and surface contact area on the lower limb. The analysis results indicated that the stiffness design of external shell and bladder, initial thickness, and morphology of the PSA, pump controller setting (the pneumatic air mass flow), and users' biological properties (e.g., limb tissue stiffness) influence pressure dosage delivery and fitting effect (contacting condition) of the PSA when it is applied on the lower limb in use.

The pneumatic pressure inside the bladder of the PSA unit can be augmented by increasing the pneumatic air mass flow, bladder stiffness, or reducing the contact surface area (i.e., bladder size or volume). The contact pressure delivered by the PSA can be increased by raising the stiffness of the bladder and the air mass flow input or reducing the initial thickness (i.e., volume) of bladders. The varied contact pressures (or pressure dosages) can transmit from the skin surface to the deeper tissues, and exert biomechanical function to the vascular system for promotion of fluid circulation (e.g., venous return or lymphatic movement).

This study presented an integrative modeling and experimental method and provided theoretical guidance on technical design of pneumatic compression devices. Its results provided a novel insight on quantitative relationships among multiple design parameters of the PSA-lower limb system, which contribute to creating more programmable and dynamic compression therapeutic devices for venous hemodynamic improvement and lower limb rehabilitation.

\section{Author Disclosure Statement}

No competing financial interests exist.

\section{Funding Information}

This study is supported by the Innovation and Technology Fund of Hong Kong SAR Government (grant no. ITS/ 031/17), the Central Research Grant of the Hong Kong Polytechnic University (grant no. 1-ZVLQ), the University Grants Committee (grant no. 1-ZE7K), the Natural Science Foundation of Jiangsu Province (grant no. BK20180933), the Natural Science Foundation of Jiangsu Higher Institutions (grant no. 19KJB460028), and the QingLan Project of Yangzhou University.

\section{Supplementary Material}

Supplementary Data

Supplementary Figure S1

Supplementary Figure S2

\section{References}

1. Wang Z, Polygerinos P, Overvelde JT, et al. Interaction forces of soft fiber reinforced bending actuators. IEEE/ ASME Trans Mechatron 2017;22:717-727.

2. Rus D, Tolley MT. Design, fabrication and control of soft robots. Nature 2015;521:467.
3. Connolly F, Walsh CJ, Bertoldi K. Automatic design of fiber-reinforced soft actuators for trajectory matching. Proc Natl Acad Sci 2017;114:51-56.

4. Belding L, Baytekin B, Baytekin HT, et al. Slit tubes for semisoft pneumatic actuators. Adv Mater 2018;30:1704446.

5. Park Y-L, Chen BR, Pérez-Arancibia NO, et al. Design and control of a bio-inspired soft wearable robotic device for ankle-foot rehabilitation. Bioinspir Biomim 2014;9:016007.

6. Marchese AD, Onal CD, Rus D. Autonomous soft robotic fish capable of escape maneuvers using fluidic elastomer actuators. Soft Robot 2014;1:75-87.

7. Tang Y, Zhang Q, Lin G, et al. Switchable adhesion actuator for amphibious climbing soft robot. arXiv 2018:180408692.

8. Cappello L, Galloway KC, Sanan S, et al. Exploiting textile mechanical anisotropy for fabric-based pneumatic actuators. Soft Robot 2018;5:662-674.

9. Miriyev A, Stack K, Lipson H. Soft material for soft actuators. Nat Commun 2017;8:596.

10. Polygerinos P, Correll N, Morin SA, et al. Soft robotics: review of fluid-driven intrinsically soft devices; manufacturing, sensing, control, and applications in human-robot interaction. Adv Eng Mater 2017;19:1700016.

11. Yoshida S, Morimoto Y, Zheng L, et al. Multipoint bending and shape retention of a pneumatic bending actuator by a variable stiffness endoskeleton. Soft Robot 2018;5:718-725.

12. Paternò L, Tortora G, Menciassi A. Hybrid soft-rigid actuators for minimally invasive surgery. Soft Robot 2018;5: 783-799.

13. Shintake J, Cacucciolo V, Shea H, et al. Soft biomimetic fish robot made of dielectric elastomer actuators. Soft Robot 2018;5:466-474.

14. Amiri Moghadam AA, Alaie S, Deb Nath S, et al. Laser cutting as a rapid method for fabricating thin soft pneumatic actuators and robots. Soft Robot 2018;5:443-451.

15. Guo J, Elgeneidy K, Xiang C, et al. Soft pneumatic grippers embedded with stretchable electroadhesion. Smart Mater Struct 2018;27:055006.

16. Tawk C, In Het Panhuis M, Spinks GM, et al. Bioinspired 3D printable soft vacuum actuators for locomotion robots, grippers and artificial muscles. Soft Robot 2018;5:685-694.

17. Hsu H, Liu L-Y, Liu L-Y, et al. 3D manufactured, waterpowered soft actuators for orthodontic application. Smart Mater Struct 2018;27:084006.

18. Schaffner M, Faber JA, Pianegonda L, et al. 3D printing of robotic soft actuators with programmable bioinspired architectures. Nat Commun 2018;9:878.

19. Moseley P, Florez JM, Sonar HA, et al. Modeling, design, and development of soft pneumatic actuators with finite element method. Adv Eng Mater 2016;18:978-988.

20. Polygerinos P, Wang Z, Overvelde JT, et al. Modeling of soft fiber-reinforced bending actuators. IEEE Trans Robot 2015;31:778-789.

21. Chen F, Dirven S, Xu W, et al. Large-deformation model of a soft-bodied esophageal actuator driven by air pressure. IEEE/ASME Trans Mechatron 2017;22:81-90.

22. Yan J, Zhang X, Xu B, et al. A new spiral-type inflatable pure torsional soft actuator. Soft Robot 2018;5:527-540.

23. Schimmack M, Haus B, Mercorelli P. An extended Kalman filter as an observer in a control structure for health monitoring of a metal-polymer hybrid soft actuator. IEEE/ ASME Trans Mechatron 2018;23:1477-1487.

24. Gerboni G, Diodato A, Ciuti G, et al. Feedback control of soft robot actuators via commercial flex bend sensors. IEEE/ASME Trans Mechatron 2017;22:1881-1888. 
25. Li Y, Chen Y, Ren T, et al. Precharged pneumatic soft actuators and their applications to untethered soft robots. Soft Robot 2018;5:567-575.

26. Cianchetti M, Laschi C, Menciassi A, et al. Biomedical applications of soft robotics. Nat Rev Mater 2018;3:143-153.

27. Li Z, Wu L, Ren H, et al. Kinematic comparison of surgical tendon-driven manipulators and concentric tube manipulators. Mech Mach Theory 2017;107:148-165.

28. Belforte G, Eula G, Ivanov A, et al. Soft pneumatic actuators for rehabilitation. Actuators 2014;3:84-106.

29. Li Y, Hashimoto M. PVC gel soft actuator-based wearable assist wear for hip joint support during walking. Smart Mater Struct 2017;26:125003.

30. Maeder-York P, Clites T, Boggs E, et al. Biologically inspired soft robot for thumb rehabilitation. J Med Devices 2014;8:020933.

31. Li Y, Hashimoto M. PVC gel based artificial muscles: characterizations and actuation modular constructions. Sens Actuators A 2015;233:246-258.

32. Li Y, Hashimoto M. Design and prototyping of a novel lightweight walking assist wear using PVC gel soft actuators. Sens Actuators A 2016;239:26-44.

33. Li Y, Maeda Y, Hashimoto M. Lightweight, soft variable stiffness gel spats for walking assistance. Int J Adv Robot Syst 2015;12:175.

34. Singh G, Xiao C, Hsiao-Wecksler ET, et al. Design and analysis of coiled fiber reinforced soft pneumatic actuator. Bioinspiration Biomimetics 2018;13:036010.

35. Xiao C, Oo YL, Farooq D, et al. Pneumatic sleeve orthosis for Lofstrand crutches: application of soft pneumatic FREE actuator. J Med Devices 2016;10:020959.

36. Xiao CZ, Jahanian O, Schnorenberg AS, et al. Design and biomechanical evaluation methodology of pneumatic ergonomic crutch. Proceedings of the 2017 Design of Medical Devices Conference, April 10-13, 2017, Minneapolis, MN, USA. DOI: 10.1115/DMD2017-3512

37. Singh G, Xiao CZ, Krishnan G, Hsiao-Wecksler E. Design and analysis of soft pneumatic sleeve for arm orthosis. International Design Engineering Technical Conferences and Computers and Information in Engineering Conference, August 21-24, 2016, Charlotte, NC, USA. DOI: 10.1115/DETC2016-59836

38. Ghate S, Kulikovskis G, Shanmuganathan V (Eds). Design and development of soft actuator for surgical application. In 2017 International Conference on Data Management, Analytics and Innovation (ICDMAI). Pune, India: IEEE, 2017.

39. Low F-Z, Tan HH, Lim JH, et al. Development of a soft pneumatic sock for robot-assisted ankle exercise. J Med Devices 2016;10:014503-014505.

40. Young AJ, Ferris DP. State of the art and future directions for lower limb robotic exoskeletons. IEEE Trans Neural Syst Rehabil Eng 2017;25:171-182.

41. Kang R, Guo Y, Cheng K, et al. Design and control of a soft actuator driven by pneumatic muscles. In 2014 International Conference on Industrial Automation, Information and Communications Technology (IAICT). IEEE, 2014.

42. Yamany A, Hamdy B. Effect of sequential pneumatic compression therapy on venous blood velocity, refilling time, pain and quality of life in women with varicose veins: a randomized control study. J Phys Ther Sci 2016;28:1981-1987.

43. Grand View Research. Compression therapy market size, share \& trends analysis report by technology (static compression therapy, dynamic compression therapy), by product, by region, and segment forecasts, 2018-2025. https:// www.grandviewresearch.com/industry-analysis/compressiontherapy-market (accessed December 2018).

44. Campbell W, Decaluwe H, Macintyre J, et al. Most patients with varicose veins have fears or concerns about the future, in addition to their presenting symptoms. Eur J Vascular Endovasc Surg 2006;31:332-334.

45. Griffin M, Kakkos S, Geroulakos G, et al. Comparison of three intermittent pneumatic compression systems in patients with varicose veins: a hemodynamic study. Int Angiol 2007;26:158.

46. Keith SL, McLaughlin DJ, Anderson FA, et al. Do graduated compression stockings and pneumatic boots have an additive effect on the peak velocity of venous blood flow? Arch Surg 1992;127:727-730.

47. Malone MD, Cisek PL, Comerota Jr AJ, et al. Highpressure, rapid-inflation pneumatic compression improves venous hemodynamics in healthy volunteers and patients who are post-thrombotic. J Vasc Surg 1999;29:593-599.

48. Jacobs DG, Piotrowski JJ, Hoppensteadt DA, et al. Hemodynamic and fibrinolytic consequences of intermittent pneumatic compression: preliminary results. J Trauma Acute Care Surgery 1996;40:710-717.

49. Comerota AJ, Chouhan V, Harada RN, et al. The fibrinolytic effects of intermittent pneumatic compression: mechanism of enhanced fibrinolysis. Ann Surg 1997;226:306.

50. Smith PC, Sarin S, Hasty J, et al. Sequential gradient pneumatic compression enhances venous ulcer healing: a randomized trial. Surgery 1990;108:871-875.

51. McCulloch JM, Marler KC, Neal MB, et al. Intermittent pneumatic compression improves venous ulcer healing. Adv Wound Care 1994;7:22-46.

52. Morris RJ, Woodcock JP. Intermittent pneumatic compression or graduated compression stockings for deep vein thrombosis prophylaxis? A systematic review of direct clinical comparisons. Ann Surg 2010;251:393-396.

53. Dai G, Gertler J, Kamm R. The effects of external compression on venous blood flow and tissue deformation in the lower leg. J Biomech Eng 1999;121:557-564.

54. Bertetto AM, Meili S, Ferraresi C, et al. A mechatronic pneumatic device to improve diastolic function by intermittent action on lower limbs. Int J Autom Technol 2017;11:501.

55. ISO. Pneumatic fluid power-Determination of flow-rate characteristics of components using compressible fluids-Part 2: Alternative test methods. ISO 6358-2:2013. https://www.sis.se/ api/document/preview/916178/ (accessed October 2018).

56. Yang F, Li G, Hu D, et al. A new method for calculating the sonic conductance of airflow through a short-tube orifice. Adv Mech Eng 2017;9:1687814016687264.

57. Yang Y, Zhang Y, Kan Z, et al. Hybrid jamming for bioinspired soft robotic fingers. Soft Robot. 2019. DOI: 10.1089/soro.2019.0093.

58. Hasse A, Mauser K. Poisson induced bending actuator for soft robotic systems. Soft Robot 2019. DOI: 10.1089/soro .2018.0163.

Address correspondence to: Rong Liu ST705, Core $S, 7 / F$ Institute of Textiles and Clothing The Hong Kong Polytechnic University Hung Hom, Kowloon Hong Kong

E-mail: rong.liu@polyu.edu.hk 